\title{
Foix-Alajouanine Syndrome Mimicking Longitudinally Extensive Transverse Myelitis
}

\author{
Anirudha S Rathnam ${ }^{1}$, Anza B Memon ${ }^{1,2}$ \\ ${ }^{1}$ Department of Neurology, Henry Ford Health System, Detroit, Michigan, USA \\ ${ }^{2}$ Wayne State University, School of Medicine, Detroit, Michigan, USA
}

Received: $14 / 10 / 2020$

Accepted: $20 / 10 / 2020$

Published: $10 / 11 / 2020$

How to cite this article: Rathnam AS, Memon AB. Foix-Alajouanine syndrome mimicking longitudinally extensive transverse myelitis. EJCRIM 2020;7: doi:10.12890/2020_002063.

Conflicts of Interests: The Authors declare that there are no competing interests.

This article is licensed under a Commons Attribution Non-Commercial 4.0 License

\section{ABSTRACT}

Foix-Alajouanine syndrome is an arteriovenous malformation causing subacute congestive myelopathy that can lead to progressive paraplegia. It typically affects the lower thoracic and lumbosacral levels. Arteriovenous fistula (AVF) leads to increased venous pressure, decreasing the arteriovenous pressure gradient and leading to a decrease in spinal cord perfusion, oedema and necrosis. Early recognition and surgical intervention can result in a good prognosis.

\section{LEARNING POINTS}

- Spinodural arteriovenous fistula (SDAF) can present with longitudinally extensive transverse myelitis (LETM), progressive gait instability, and lower extremity weakness.

- Failure to promptly recognize this condition and misdiagnosis can result in a poor outcome.

- Microsurgical obliteration of the SDAF provides better results than embolization.

\section{KEYWORDS}

Longitudinally extensive transverse myelitis, LETM, spinodural arteriovenous fistula, SDAF, artery of Adamkiewicz

\section{INTRODUCTION}

In 1926, Drs Foix and Alajouanine described subacute congestive myelopathy leading to progressive paraplegia and the eventual death of two men. Spinal cord necrosis and multiple tortuous, thickened blood vessels on the spinal cord surface were seen on autopsy. They called the condition necrotizing myelopathy ${ }^{[1]}$. Several years later, this necrotizing myelopathy was associated with the presence of a small but abnormal connection between a radicular vein and artery, or arteriovenous fistula (AVF). AVF can cause increased venous pressure, decrease the arteriovenous pressure gradient, and decrease spinal cord perfusion, leading to spinal cord oedema. The lower part of the spinal cord is most often affected due to gravity and lack of valves in the intraspinal venous system ${ }^{[2]}$. Foix-Alajouanine syndrome continues to be a rare condition. A neurologist may only see one case approximately every $4-8$ years ${ }^{[2]}$. It is also often misdiagnosed, underdiagnosed or diagnosed late, resulting in ineffective treatment or surgery and a poor outcome ${ }^{[2,3]}$. We present one such case with unique radiographic findings and relatively early diagnosis, treatment and better clinical outcomes. 


\section{CASE DESCRIPTION}

A 77-year-old man presented to the clinic with an 8-month history of progressive lower extremity weakness, paraesthesia, gait instability, and recurrent falls to the point that he had fractured his orbital floor. He had no lumbar or leg pain. He had no urinary sphincter dysfunction. The patient was diagnosed with lumbar spinal stenosis and underwent L3-L4 lumbar decompression with no improvement. Electromyography was normal. MRI of the lumbar spine without contrast (Fig. 1A,B) showed longitudinally extensive transverse myelitis (LETM) from T8 through the tip of the conus medullaris and flow voids at the dorsal aspect of T9-L1 consistent with a type I spinal dural arteriovenous fistula (SDAF) diverting flow from the artery of Adamkiewicz, confirmed by the spinal angiogram (Fig. 1C).

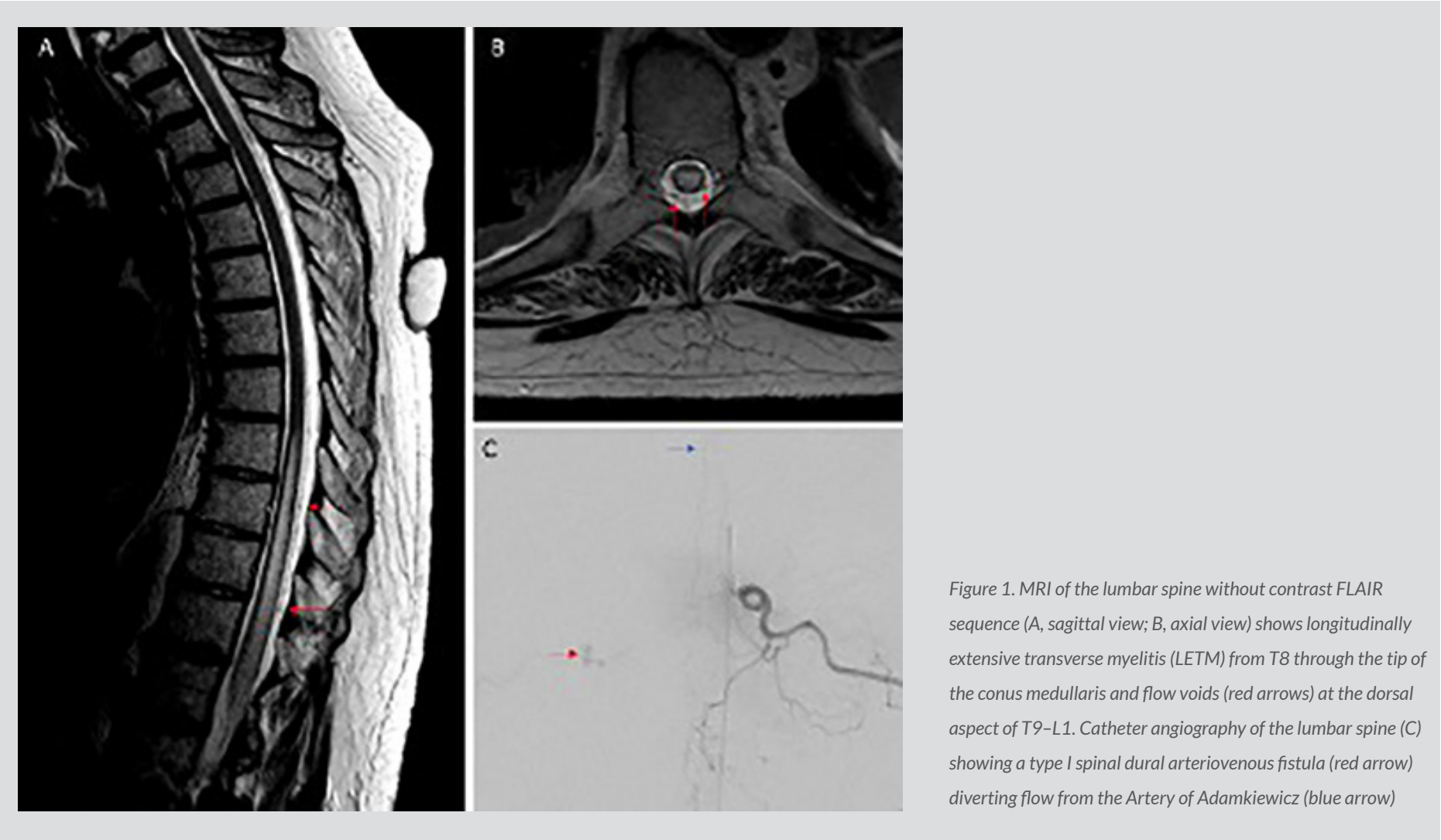

Given the presence of LETM on neuroimaging, demyelinating inflammatory work-up including a normal brain MRI and cerebrospinal fluid analysis was completed. The patient tested negative for aquaporin-4 antibody and myelin oligodendrocyte glycoprotein (MOG) antibody. He underwent microsurgical obliteration of the SDAF and regained $50 \%$ of his lower extremity strength within 48 hours and continued to improve at the rehabilitation centre.

\section{DISCUSSION}

Patients with Foix-Alajouanine syndrome often present with subacute spastic paraparesis which can progress over 1-5 years to flaccid paraparesis. They may also exhibit gait imbalance, frequent falls, unilateral or bilateral symmetric or asymmetric numbness, tingling, weakness, and urinary or faecal retention or incontinence ${ }^{[4]}$. They can have lumbar pain with or without radicular symptoms. Interestingly, our patient did not exhibit any urinary sphincter dysfunction, which was attributed to the fact that the disease was still in the early phase ${ }^{[2]}$. The differential diagnosis includes demyelinating inflammatory conditions, syphilis, spinal cord haemorrhage and infarction, human T cell lymphotropic viruses (HTLV), HIV infections and AIDS, syringomyelia, and vitamin B12-associated neurological diseases. The therapeutic approach consists of surgical ligation of the fistula, vascular embolization or/and surgical obliteration of the $\operatorname{SDAF}^{[5,6]}$.

\section{CONCLUSION}

We present an interesting case of an AVF presenting with neuroimaging features of LETM. This patient showed progressive lower extremity weakness with no improvement in his symptoms after lumbar surgery. The autoimmune inflammatory work-up was negative for LETM. 


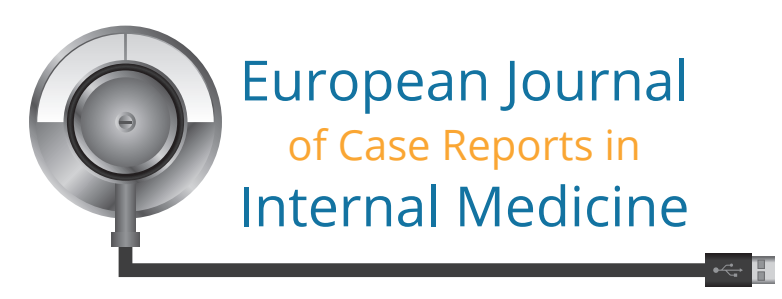

MRI of the lumbar spine showing flow voids raised concern for AVF, which was confirmed by the spinal angiogram. Delay in recognising this condition can result in poor outcomes. Direct surgical obliteration of the SDAF provides better results and lower recurrence rates than embolization ${ }^{[6-8]}$.

\section{REFERENCES}

1. Foix C, Alajouanine T. La myélite nécrotique subaigue. Rev Neurol (Paris) 1926;2:1-42.

2. Jellema K, Tijssen CC, van Gijn J. Spinal dural arteriovenous fistulas: a congestive myelopathy that initially mimics a peripheral nerve disorder. Brain 2006;129:3150-3164.

3. Nasr DM, Brinjikji W, Rabinstein AA, Lanzino G. Clinical outcomes following corticosteroid administration in patients with delayed diagnosis of spinal arteriovenous fistulas. J Neurointerv Surg 2017;9(6):607-610.

4. Kumar A, Deopujari CE, Mhatre M. Misdiagnosis in a case of non-compressive myelopathy due to a lumbar spinal intradural fistula supplied by the Artery of Adamkiewicz. Surg Neurol Int 2011;2:12.

5. Jellema K, Tijssen CC, van Gijn J. Spinal dural arteriovenous fistulas: a congestive myelopathy that initially mimics a peripheral nerve disorder. Brain 2006;129(Pt 12):31503164.

6. Sivakumar W, Zada G, Yashar P, Giannotta SL, Teitelbaum G, Larsen DW. Endovascular management of spinal dural arteriovenous fistulas. A review. Neurosurg Focus 2009;26(5):E15.

7. Steinmetz MP, Chow MM, Krishnaney AA, Andrews-Hinders D, Benzel EC, Masaryk TJ, et al. Outcome after the treatment of spinal dural arteriovenous fistulae: a contemporary single-institution series and meta-analysis. Neurosurgery 2004;55:77-87.

8. Andres RH, Barth A, Guzman R, Remonda L, El-Koussy M, Seiler RW, et al. Endovascular and surgical treatment of spinal dural arteriovenous fistulas. Neuroradiology 2008;50(10):869-876 